\title{
EDUCAÇÃO CONTINUADA EM ESCOLAS DE GOVERNO: USO DE ANDRAGOGIA NO DESENVOLVIMENTO DE COMPETENCIAS PROFISSIONAIS
}

\author{
Alessandra de Souza Santos* \\ Frederico de Carvalho Figueiredo ${ }^{* *}$
}

RESUMO: A andragogia representa um caminho consolidado de desenvolvimento profissional e de lideranças, podendo ser integrada à adoção de um conjunto de práticas e comportamentos que visam à geração contínua de conhecimento a ser difundida por toda a organização. Enfatiza-se também a importância que tem ganhado a educação continuada e o desenvolvimento de competências no âmbito do serviço público em várias esferas e poderes. O presente trabalho teve por objetivo primordial aprofundar o conhecimento sobre a abordagem andragógica de ensino e aprendizagem com o intuito de demonstrar a importância do uso de uma abordagem andragógica para subsidiar uma futura implantação de programa curricular baseado no desenvolvimento de competências profissionais em Escolas de Governo, em um contexto de educação continuada. Objetivou-se, em específico, conceituar a educação continuada; conceituar andragogia, e demonstrar sua importância no aperfeiçoamento de adultos e no desenvolvimento de lideranças; apresentar o histórico e o papel das Escolas de Governo; e sugerir competências para o serviço público, com base na pesquisa bibliográfica sobre o tema. A pesquisa consistiu de um estudo com objetivo exploratório, abordagem qualitativa e a coleta de dados foi feita por meio de pesquisa bibliográfica e pesquisa documental.

PALAVRAS-CHAVE: Andragogia; Competências; Educação Continuada; Escola de Governo.

\section{CONTINUOUS EDUCATION IN GOVERNMENT-RUN SCHOOLS: THE USE OF ANDRAGOGY IN THE DEVELOPMENT OF PROFESSIONAL COMPETENCES}

ABSTRACT: Andragogy is the consolidated route of professional development and leadership. It may be integrated to a series of practices and behaviors aiming at the

Mestranda em Gestão Social, Educação e Desenvolvimento Local pelo Centro Universitário UNA (UNA-BH), Brasil. E-mail: alessandra@mpmg.mp.br

** Doutor em Gestão Urbana pela Pontifícia Universidade Católica do Paraná (PUC/PR); Docente/Pesquisador do Programa de Pós-Graduação em Gestão Social, Educação e Desenvolvimento Local, Centro Universitário Una, Brasil. 
continuous generation of knowledge disseminated throughout the entire organization. The importance of continuous education and the development of competences within the public service in several environments should be emphasized. Current analysis is an in-depth knowledge on the andragogical approach in teaching and learning to demonstrate its use for foregrounding a future establishment of a curricular program based on the development of professional competences in government -run schools within the context of continuous education. Specifically, the notion of continuous education and andragogy should be investigated; its importance in the improvement adults and in the development of leaders should be demonstrated; the role and history of government-run school should be forwarded; and competences for the public service, based on a bibliographic research on the theme are suggested. Current research comprises an exploratory study with a qualitative approach and collection of data through bibliographical and documental research.

KEY WORDS: Andragogy; Competences; Continuous education; Government-run school.

\section{INTRODUÇÃO}

O paradigma da era do conhecimento nos obriga a repensar criticamente o papel das Escolas de Governo, órgãos de formação e aperfeiçoamento de servidores públicos, assim como propor uma abordagem pedagógica condizente com essa nova realidade, uma vez que somos bombardeados continuamente por informações, que nos chegam por diferentes meios de comunicação (CARDOSO, 2006). A quantidade imensa de dados e informações e o fácil acesso a fontes de informação retiraram o professor do seu papel tradicional de "detentor" e de "transmissor" do conhecimento (MASETTO, 2011), o que reflete na necessidade de se questionar o modelo tradicional de ensino e aprendizagem. Fazendo-se um paralelo com o proposto por Masetto (2011) no ensino superior, a demanda atual é por servidores capazes de buscar, selecionar, organizar e analisar novas informações, integrando-as à sua realidade para aprimorar processos de trabalho. A abordagem baseada na andragogia vem ao encontro dessa necessidade e é um caminho consolidado de desenvolvimento profissional de competências e de lideranças (BECKER et al., 2014), podendo ser integrada à adoção de um conjunto de práticas e comportamentos que visam à geração contínua de conhecimento a ser difundida por toda a organização, de forma 
alinhada à missão, visão e objetivos institucionais.

Enfatiza-se a importância que tem ganhado a educação continuada e o desenvolvimento de competências na esfera do serviço público. Houve a normatização em âmbito federal, por meio do Decreto $n^{0} 5.707$, de 23 de fevereiro de 2006 (BRASIL, 2017d), que instituiu a Política e as Diretrizes para o Desenvolvimento de Pessoal da Administração Pública Federal direta, autárquica e fundacional, definindo a gestão por competências. Também o Tribunal de Contas da União (TCU) proferiu o Acórdão $\mathrm{n}^{\mathrm{O}}$ 3.023/2013 (BRASIL, 2017e), indicando a gestão por competências como instrumento para a governança estratégica de pessoas. No âmbito do Poder Judiciário, o Conselho Nacional de Justiça (CNJ) instituiu a Resolução ${ }^{0}$ 192, de 08 de maio de 2014 (BRASIL, 2017b), que dispõe sobre a Política Nacional de Formação e Aperfeiçoamento dos Servidores do Poder Judiciário e estabelece que o CNJ identificará as competências funcionais (conhecimentos, habilidades e atitudes) a serem desenvolvidas nos servidores do Poder Judiciário. No âmbito do Ministério Público, o Conselho Nacional do Ministério Público (CNMP) recomendou que os Ministérios Públicos brasileiros implementem a Política Nacional de Gestão de Pessoas, por meio da Recomendação $n^{0}$ 52, de 28 de março de 2017 (BRASIL, 2017c).

O presente estudo consiste em uma revisão de literatura para levantar subsídios teóricos objetivando a uma futura proposição de modelo de educação continuada (lifelong learning), baseado em conceitos andragógicos de ensino e aprendizagem em programas curriculares de Escolas de Governo do setor público brasileiro, com a finalidade de se desenvolver competências profissionais e de liderança. Nesse contexto, faz-se necessário também analisar criticamente o papel das Escolas de Governo, procurando demonstrar a importância do uso da andragogia no aperfeiçoamento continuado de pessoas, com vistas à formação de competências profissionais. $\mathrm{O}$ trabalho tem por objetivo primordial aprofundar o conhecimento sobre a abordagem andragógica de ensino e aprendizagem com o intuito de demonstrar sua importância em um contexto de educação continuada para o desenvolvimento de competências profissionais e de liderança em Escolas de Governo.

O método utilizado na pesquisa, em relação ao seu objetivo geral, foi um estudo exploratório, para aprofundar o conhecimento sobre o tema. A pesquisa teve natureza qualitativa, cuja coleta de dados foi feita por meio de pesquisa documental 
e pesquisa bibliográfica. A pesquisa documental consistiu em pesquisa de legislação e atos normativos oficiais, disponíveis em portais institucionais (extranet) de diversos órgãos públicos.

\section{EDUCAÇÃO CONTINUADA E ANDRAGOGIA}

No cenário atual, a constância e a turbulência gerada por mudanças dão a tônica para que a formação de pessoas seja cada vez mais focada na autonomia de aprendizagem e na capacidade de aprender continuamente. Takeuchi e Nonaka (2008) citam Schumpeter, para quem o "desequilíbrio dinâmico" é o único estado estável da economia e a "destruição criativa" da inovação, a força impulsora da economia. Nesse cenário de instabilidade, acredita-se que a andragogia seja uma abordagem que possibilite a educação continuada.

\subsection{A EDUCAÇÃO CONTINUADA}

Segundo Lévy (1995, apud CARDOSO, 2006, p. 17) o saber gerado pela humanidade "é incontável, intangível e infinitamente variável, se agrupa e se fragmenta numa infinidade de conhecimentos prontos para serem usados [...]". Cardoso (2006) enfatiza a necessidade de saber lidar com o fluxo de informação disponível e cita Kegan, para quem as expectativas que a sociedade contemporânea coloca para o adulto demandam "algo maior do que o simples comportamento, a aquisição de habilidades específicas ou o domínio de um determinado conhecimento" (KEGAN, 2002, apud CARDOSO, 2006, p. 18). Meister (1999, p. 7) afirma que as organizações precisam abraçar a mudança de maneira proativa, uma vez que "a capacidade de ajustar e aperfeiçoar sistemas e processos passa a ser uma questão de sobrevivência". Essa demanda social crescente exercida em plena era do conhecimento gera a necessidade de aprendizagem continuada ou aprendizagem ao longo da vida.

A era do conhecimento trouxe novos paradigmas para a prestação de serviços, com a incorporação de novas tecnologias ao uso diário e profissional, demandando novas competências no ambiente corporativo. Vivenciamos o que Castells 
definiu como uma "nova forma de organização social, caracterizada pela globalização das atividades econômicas, por sua forma de organização em redes, pela flexibilidade, insegurança e individualização da mão-de-obra" (apud SOUZA, 2011, p. 1). Nesse contexto, a prestação de serviços públicos também sofreu o impacto do aumento da demanda e da cobrança social por qualidade e eficiência. Atividades intensivas em conhecimento exigem uma mão de obra altamente qualificada e propensa a "aprender a aprender", isto é, deve estar aberta a novas ideias, habilidades e comportamentos, o que se convencionou designar educação continuada (lifelong learning). $\mathrm{O}$ aprimoramento continuado é imprescindível nessa realidade, pois o capital intelectual das instituições torna-se o diferencial competitivo do órgão público no cumprimento de sua missão institucional (CHRISPIM; TORRES, 2014). Nesse novo cenário, as competências centrais comuns do ambiente de trabalho, segundo Meister (1999, p. 13), são: "aprender a aprender; comunicação e colaboração; raciocínio criativo e resolução de problemas; conhecimento tecnológico; conhecimento de negócios globais; desenvolvimento de liderança e autogerenciamento de carreira".

Nesse contexto, a educação continuada dos servidores torna-se fundamental para o autodesenvolvimento. É preciso aprender a aprender e o aprendizado organizacional 'tem como foco a organização que 'aprende', isto é, que desenvolve habilidades para identificar, adquirir, resgatar, criar e transferir conhecimento, modificando seu comportamento ao refletir novos conhecimentos e novas formas de pensar e agir" (TARAPANOFF, 2012, p. 19). Ademais, "Ao sustentar-se no aprendizado contínuo e na autorrenovação constante, a organização tem em vista o alinhamento contínuo de suas competências em relação a seus objetivos estratégicos" (TARAPANOFF, 2012, p. 19). Dessa forma, é possível mudar paradigmas, disseminando saberes e compartilhando o conhecimento, de forma a permitir o desenvolvimento do capital humano, com foco na missão, nos valores e nos objetivos da instituição.

Segundo Jacques Delors e colaboradores (1996), no Relatório para a UNESCO da Comissão Internacional sobre Educação para o século XXI,

A educação ao longo de toda a vida é uma construção contínua da pessoa humana, do seu saber e das suas aptidões, mas também da sua capacidade de discernir e agir. Deve levá-la a tomar consciência de si própria e do meio que a envolve e a desempenhar o papel social que lhe cabe no mundo do trabalho e na comunidade (UNESCO, 
1996, p. 106).

Segundo Jacques Delors e colaboradores (1996), a educação ao longo de toda a vida baseia-se em quatro pilares: aprender a conhecer, aprender a fazer, aprender a viver juntos, aprender a ser. Segundo os autores, o ensino formal orienta-se quase que exclusivamente para o "aprender a conhecer" e, em menor escala, para o "aprender a fazer". Mas o que é "aprendizagem", afinal? Para Pozo (2002 apud BRANDÃO, 2009, p. 59), a aprendizagem constitui "a possibilidade de a pessoa modificar seu comportamento diante de mudanças no ambiente”. Segundo Brandão (2009),

Aprender implica mudar conhecimentos, habilidades ou atitudes anteriores. Constitui uma mudança relativamente duradoura na capacidade ou no comportamento da pessoa, transferível para as novas situações com as quais ela se depara (GAGNÉ; MEDSKER, 1996; SONNENTAG et al., 2004). A aprendizagem, então, pode ser vista como um processo dinâmico, que gera mudanças qualitativas na forma pela qual uma pessoa vê, experimenta, entende e conceitua algo (MATHEWS; CANDY 1999; GAGNÉ; MEDSKER, 1996; SONNENTAG ET AL., 2004 APUD BRANDÃO, 2009, P. 59).

Segundo Brandão (2009), a partir de pesquisa sobre o trabalho de diversos autores, sugere-se que a aprendizagem seja influenciada tanto por variáveis contextuais quanto por características do indivíduo, sendo a motivação um importante fator que influencia o sucesso da aprendizagem, tanto em contextos de trabalho como em situações educacionais. Isso ocorreria porque,

Segundo Pozo (2002), aprender exige a mobilização do sistema cognitivo, mediante a utilização de múltiplos processos que vão além dos mecanismos de aquisição e mudança de conhecimentos. A aprendizagem, portanto, supõe um esforço que requer motivação, o que implica mudar as prioridades de uma pessoa. Os motivos para aprender, por sua vez, precisam ser suficientes para superar eventuais dificuldades (BRANDÃO, 2009, p. 75).

Pozo (2002 apud BRANDÃO, 2009, p. 76) classifica os motivos para a pessoa aprender como de "natureza extrínseca - quando estão relacionados às conseqüências da aprendizagem - e de natureza intrínseca - quando se referem à satisfação pessoal por aprender, e não às decorrências da aprendizagem". Segundo o autor, os resultados obtidos quando a aprendizagem é movida pela motivação intrínseca são 
mais duradouros e consistentes.

Em relação à aprendizagem, Brandão (2009, p. 62) sugere que, como esta "implica mudar conhecimentos, habilidades e atitudes, pode, por conseguinte, promover o desenvolvimento de competências profissionais". Mas, segundo Delors e colaboradores (1996) a educação ao longo de toda a vida vai ainda mais longe.

[A educação ao longo da vida] Deve fazer com que cada indivíduo saiba conduzir o seu destino, num mundo onde a rapidez das mudanças se conjuga com o fenômeno da globalização para modificar a relação que homens e mulheres mantêm com o espaço e o tempo. As alterações que afetam a natureza do emprego, ainda circunscritas a uma parte do mundo, vão, com certeza, generalizar-se e levar a uma reorganização dos ritmos de vida. A educação ao longo de toda a vida torna-se assim, para nós, o meio de chegar a um equilíbrio mais perfeito entre trabalho e aprendizagem bem como ao exercício de uma cidadania ativa (UNESCO, 1996, p. 105).

Colquitt e colaboradores (2000, apud BRANDÃO, 2009, p. 75) verificaram que a motivação para aprender estava "significativamente relacionada a resultados de ações instrucionais, tais como o desenvolvimento de competências profissionais e sua transferência para o trabalho".

Sobre a motivação, Durán (2012) afirma que, com a substituição do trabalho humano menos complexo, rotineiro e algorítmico, comum durante o século XX, por computadores, robôs ou inteligência artificial, essa nova configuração mundial exerce grande impacto na motivação das pessoas no trabalho. Espera-se que os trabalhadores sejam cada vez mais automotivados e auto-orientados. Durán cita também Daniel Pink (2010), para quem a motivação extrínseca derivada de recompensas pode alcançar resultados opostos, diminuindo a motivação ao invés de aumentá-la, pois os trabalhadores podem ficar condicionados a trabalharem somente até o momento em que a recompensa é acionada.

Nesse contexto, torna-se importante enfatizar o papel da abordagem andragógica para fomentar a motivação intrínseca do aprendiz.

\subsection{ANDRAGOGIA}

O termo "andragogia" vem do grego andros (adulto) e agogus (liderar, con- 
duzir, guiar) e significa "a arte e ciência de auxiliar adultos a aprenderem" (KNOWLES, 1980 apud MERRIAM; CAFFARELLA; BAUMGARTNER, 2007, p. 84). Pedagogia deriva do grego "paid", que significa criança e "agogus", que significa "a arte e ciência de auxiliar crianças a aprenderem" (KNOWLES, 1980 apud MERRIAM; CAFFARELLA; BAUMGARTNER, 2007, p. 84).

Segundo Shinoda e colaboradores (2014), os conceitos de pedagogia (ensino de crianças) e andragogia (ensino de adultos) não são opostos, mas complementares. DeAquino (2015, p. 12) assevera que a pedagogia e a andragogia se encontram em extremidades opostas de um contínuo e apresentam "diferenças significativas na maneira de abordar o aprendiz, o ambiente de aprendizagem e a forma como ocorre a interação professor-aluno", sendo a pedagogia caracterizada por uma aprendizagem direcionada, na qual o aprendiz tem maior dependência do educador e na outra extremidade está a andragogia ou aprendizagem facilitada, na qual o aprendiz, devido sua experiência de vida, tem mais independência no seu processo de aprendizagem (DEAQUINO, 2015). O aprendiz adulto é responsável por sua educação, evolução profissional e por suas decisões, sendo motivado por fatores internos.

O termo "andragogia", segundo o Nottingham Andragogy Group (apud Shinoda et al., 2014), foi cunhado por Alexander Kapp em 1833. O termo foi popularizado por Malcom Knowles em 1970, com a publicação de seu livro The modern practice of adult education. Shinoda et al. (2014) explicitam os princípios da andragogia, trazendo os conceitos elaborados por diversos autores, detalhando os princípios formulados por Knowles, Holton III e Swanson:

Os princípios formulados por Knowles, Holton III e Swanson (2009) reforçam alguns dos princípios de Lindeman (1926) e Gibb (1960). São eles: (1) a necessidade de conhecer: os adultos necessitam saber a utilidade e valor do material que eles estão usando antes de se envolverem na aprendizagem; (2) autoconceito de indivíduo: o autoconceito do adulto aprendiz é autodirecionado e autônomo; (3) o papel da experiência: as experiências prévias são o mais rico recurso disponível para o indivíduo que aprende; (4) prontidão para aprender: entre os adultos, a prontidão para aprender depende da valorização da relevância do tópico tratado e de como ele contribui para sua situação de vida e problemas; (5) orientação para a aprendizagem: a orientação dos adultos para aprender é centrada no problema, centrada na tarefa e centrada na vida; o que os motiva é perceber que o conhecimento os ajudará a desempenhar tarefas 
e resolver problemas; (6) motivação: os adultos estão direcionados principalmente por pressão interna, pela motivação, pelo desejo de autoestima e pela meta realizada (SHINODA et al, 2014, p. 513).

Em relação à necessidade de saber do aprendiz, Cardoso (2006) enfatiza a importância de se conscientizar adultos da necessidade de aprender, de modo a elevar seu nível de consciência para a necessidade de saber, para que percebam a distância entre onde estão agora e onde querem chegar. Para tanto, Cardoso (2006) menciona que é relevante que o docente explore a necessidade de saber como a aprendizagem será conduzida, que aprendizado ocorrerá e porque o aprendizado é importante.

Em relação ao autoconceito do aprendiz, ou aprendizagem autodirecionada, Cardoso (2006) explica que os adultos têm um autoconceito de serem responsáveis por suas ações e decisões, demonstrando resistência a imposições externas.

A respeito da experiência prévia, isto é, ao papel das experiências do aprendiz, Cardoso (2006) ressalta que adultos apresentam experiências prévias, necessidades, motivação, estilos de aprendizagem, interesses e metas de forma mais heterogênea. Segundo a autora,

[...] a ênfase na educação de adulto deve ser colocada na individualização das estratégias de ensino e aprendizagem. O que significa que os recursos de aprendizagem estão no adulto e as técnicas que vão explorar a experiência do aprendiz são discussóes de grupo, exercícios de simulação, atividade de solucionar problemas, estudos de casos e assistência em grupo de trabalho.

Por outro lado, esse acúmulo de experiência também pode ser negativo, pois o adulto pode ter desenvolvido hábitos mentais, predisposições que podem levá-lo a não aceitar novos modelos, abordagens e novas formas de pensar. Cabe ao educador descobrir formas de ajudar esse aprendiz a reexaminar sua postura, bem como auxiliá -lo em um movimento de abrir a sua mente para novas abordagens (CARDOSO, 2006, p. 35-36, grifo nosso).

Em relação à prontidão para aprender, Cardoso (2006) afirma que adultos geralmente apresentam prontidão para aprender na medida em que têm necessidade. Segundo ela, "quanto mais os profissionais envolvidos com educação de adultos procurarem entender a situação de vida e prontidão para aprender dos alunos, mais efetivos eles se tornarão" (CARDOSO, 2006, p. 37). Dessa forma, depreende-se que 
a prontidão para aprender é dependente da situação em que o adulto aprendiz se encontra, isto é em algumas situações demandará mais orientação e suporte do professor e em outras terá mais autonomia.

Em relação à orientação para aprendizagem, adultos possuem orientação para aprendizagem centrada em suas vidas e, segundo Cardoso (2006, p. 39), "sentem-se motivados a aprender algo a partir do momento em que percebem que o aprendizado irá ajudá-los na resolução de problemas, tarefas, ou lidar com situações do dia-a-dia".

Por fim, em relação à motivação para aprender, segundo Cardoso (2006, p. 40), "O modelo andragógico de Knowles, Holton e Swanson (1998) considera que o adulto tende a ser mais motivado para uma aprendizagem que irá ajudá-lo a resolver problemas da sua vida ou que resultará em recompensas pessoais e internas". Estudos sobre a motivação na educação demonstram que esta é mais forte quando gerada por fatores intrínsecos. Wlodowski, citado por Knowles, Horton e Swanson (1998, apud CARDOSO, 2006), acredita que o que motiva o adulto aprendiz a aprender é a soma de quatro fatores:

- Sucesso: quer ter sucesso na aprendizagem.

- Vontade: quer ter a sensação de que está aprendendo aquilo que escolheu.

- Valor: quer aprender aquilo que valoriza.

- Satisfação: a aprendizagem deve ser uma experiência de prazer (CARDOSO, 2006, p. 41).

Dessa forma, Knowles, Holton e Swanson (1998, apud CARDOSO, 2006, p. 41) concluíram que adultos se motivam quando "acreditam que podem aprender um novo conteúdo (expectativa), que a aprendizagem desse novo conteúdo ajudará a resolver problemas (instrumentalização) que são importantes na sua vida (vontade)".

Ressalte-se que St. Clair (2002, apud MERRIAM; CAFFARELLA; BAUMGARTNER, 2007) advoga que a educação de adultos e o desenvolvimento de recursos humanos estão convergindo cada vez mais. No mesmo sentido, Kessels e Poell (2004, apud MERRIAM; CAFFARELLA; BAUMGARTNER, 2007) afirmam que a andragogia, em conjunto com a teoria do capital social (redes sociais, comunidades de prática, confiança mútua) promovem o desenvolvimento de recursos humanos. 
Dessa forma, a Andragogia tem sido utilizada como importante ferramenta de educação continuada, inclusive no desenvolvimento de lideranças (BECKER et al., 2014). Merriam, Caffarella e Baumgartner (2007) tratam das críticas à andragogia, dentre elas o fato de a andragogia não levar em conta os fatores sociohistóricos do aprendiz e do posicionamento de "neutralidade" na dimensão política do ensino e aprendizagem. Entretanto, as autoras analisam pesquisas sobre a andragogia e reconhecem-na como um modelo para compreender certos aspectos do aprendizado de adultos.

\section{ESCOLAS DE GOVERNO E O DESENVOLVIMENTO DE COMPETÊNCIAS PARA O SETOR PÚBLICO}

De acordo com Fernandes (2015), o tema de criação de uma escola para a formação dos servidores públicos surgiu em dois momentos, na Era Vargas e na reforma administrativa de 1967. Segundo o autor, o termo "Escola de Governo" só viria a ser incorporado nas proposições sobre a formação e treinamento dos servidores públicos durante a reforma gerencial nos anos 1990 .

Com a Emenda Constitucional no 19 , de 04 de junho de 1998, o $\S 2^{\circ}$ do art. 39 da Constituição Federal (BRASIL, 2017a) passa a vigorar com a seguinte redação:

Art. 39 [...] § $2^{\circ}$ A União, os Estados e o Distrito Federal manterão escolas de governo para a formação e o aperfeiçoamento dos servidores públicos, constituindo-se a participação nos cursos um dos requisitos para a promoção na carreira, facultada, para isso, a celebração de convênios ou contratos entre os entes federados (BRASIL, 2017a).

Segundo Cosson (2016, p. 2), a função educacional das escolas de governo fica ainda mais evidente na redação do art. $4^{\mathrm{o}}$, do Decreto Presidencial 5.707/2006 (BRASIL, 2017d), que institui a Política e as Diretrizes para o Desenvolvimento de Pessoal da Administração Pública Federal e dispõe que as escolas de governo são: "instituições destinadas, precipuamente, à formação e ao desenvolvimento de servidores públicos, incluídas na estrutura da administração pública federal direta, autárquica e fundacional”. 
Segundo Pacheco (2002, p. 77), as Escolas de Governo são "instituições destinadas ao desenvolvimento de funcionários públicos, incluídas no aparato estatal ou fortemente financiadas por recursos orçamentários do Tesouro". Segundo Ranzini e Bryan (2017), em seu estudo que analisou diversos modelos de escolas de governo, essa terminologia

[...] vem sendo usado indistintamente por organizações públicas, privadas ou não governamentais, destinadas à formação de quadros, reciclagem de funcionários ou ainda fóruns de debate, especialmente para os poderes executivo e legislativo, nas três esferas de governo. Nogueira (2005) aponta que as escolas de governo se organizaram mediante iniciativas acadêmicas e não acadêmicas, governamentais e não governamentais, com e sem fins lucrativos. A dificuldade em relação à conceituação soma-se às diversas nomenclaturas utilizadas para designar estas unidades: Escola de Gestão Pública, Escola de Administração Pública, Escola do Serviço Público, Escola de Formação e Desenvolvimento de Servidores, Universidade Corporativa do Setor Público etc. (RANZINI; BRYAN, 2017, p. 419-420).

Os autores chamam ainda a atenção para o fato de que a ausência de normatização regulamentadora e de uma definição conceitual fundamentada e amplamente aceita resultou em instituições muito diversas, sem que houvesse discussão acerca de fatores essenciais como, por exemplo, autonomia, personalidade jurídica, subordinação ou espectro de ação.

Apesar da falta de regulamentação e demarcação conceitual, o papel assumido pelas Escolas de Governo é de extrema relevância, em razão da necessidade de se criar e desenvolver competências dos servidores públicos para atender atribuições cada vez mais abrangentes. Segundo Pacheco (2002),

[...] seu desafio hoje é capacitar os quadros existentes, sobretudo gerenciais e dirigentes, e formar novos profissionais para o setor público que se engajem na superação da cultura burocrática e no exercício dos valores republicanos.

Este novo desafio implica discutir o significado dessas escolas de governo como centros de excelência em gestão pública. Por um lado, para exercer seu novo papel, a escola de governo deve se posicionar como a escola corporativa de gestão do governo - o que se traduz por estreito alinhamento às políticas e diretrizes de governo para a melhoria da gestão pública. Por outro lado, no entanto, é fundamental exercer um papel de antecipação - em busca de novas tendências 
e melhores práticas, e ainda um papel de relevância e influência na própria formulação daquelas políticas voltadas para melhoria da gestão (PACHECO, 2002, p. 75) (grifos no original).

Aires et al. (2014) ressaltam o desenvolvimento de competências dos servidores públicos para o estabelecimento de uma administração pública ágil, eficiente e eficaz e citam Pacheco (2002), que sugere a adaptação de ferramentas modernas de gestão ao contexto do setor público para o desenvolvimento de valores e indicadores de desempenho próprios. Os autores advogam ainda que as Escolas de Governo se tornem centros de excelência e adotem melhores tendências e práticas e enfatizem a aprendizagem "por meio da resolução de problemas práticos, assim como metodologias teórico-aplicadas de ensino-aprendizagem" (AIRES et al., 2014, p. 1010).

Nesse contexto, fica evidenciada a relevância da formação e desenvolvimento de competências no âmbito do serviço público. Carbone et al. (2009, p. 56) propõem que as competências devem ser descritas "sob a forma de referenciais de desempenho, ou seja, de comportamentos passíveis de observação no ambiente de trabalho". Para o setor público, Capuano (2015) salienta que:

As competências dos postos de trabalho e de seus ocupantes não devem afrontar as competências legais dos cargos, que geralmente são mais genéricas, mas devem constituir detalhamentos das competências dos cargos em contextos específicos de trabalho efetivo nas organizações públicas (CAPUANO, 2015, p. 392).

Gramigna (2002) sugere uma relação de competências identificadas em um amplo estudo que ocorreu de 1997 a 2000 e envolveu diversos setores da sociedade. A autora propõe que a adoção de competências básicas ou core competences pode ser conjugada à descrição dos cargos como ponto de partida para o mapeamento e descrição das competências corporativas. Para tanto, é importante ter-se em mente as áreas funcionais, de maneira que as competências organizacionais mapeadas cubram todas as macroatividades da organização.

Para incentivar a autonomia do aprendiz em um contexto de aprendizagem mais amplo e o desenvolvimento de competências desejadas pela organização, Brandão (2009) sugere a adoção de trilhas de aprendizagem, que extrapolam as 
delimitações de cargos e consideram as aspirações de desenvolvimento profissional dos indivíduos. Cabe à organização construir um mapa de oportunidades de aprendizagem para o desenvolvimento das competências segundo as expectativas da organização e segundo as próprias expectativas de competências a serem desenvolvidas pelos servidores.

Dessa forma, a implantação de uma abordagem andragógica que vise ao desenvolvimento de competências nas Escolas de Governo deverá levar em consideração não somente a missão de profissionalizar servidores e modernizar o Estado, mas também sua missão de

[...] orientar - enquanto órgão de Estado ou voltado para ele - as políticas públicas, a redefinição da cultura política e das formas de vida, articulando, estimulando e coordenando - de forma sistemática - os debates sobre público e privado, novos paradigmas gerenciais, compromisso ético e formação política do cidadão e do servidor público (GARCIA; SALES, 1999, p. 84).

Garcia e Sales (1999) afirmam que é necessário investir na ampliação e qualificação, repassando conhecimentos e sistematizando experiências para integrar distintas áreas de atuação e potencializar o exercício da função de vigilância e das demais funções públicas. Os autores defendem ainda que as Escolas de Governo não se reduzam a espaços de formação de técnicos em gestão pública, mas de gestores aptos a realizar uma gestão participativa, em espaços sociais e culturais democráticos de participação dos beneficiados da gestão pública, os cidadãos.

Além disso, segundo os autores, as Escolas de Governo poderão firmar parcerias com as ONGs, funcionando com elas como uma agência de orientação, para sistematizar demandas da sociedade, apontando as políticas públicas a serem estabelecidas, fornecendo subsídios para os órgãos operacionais (públicos ou privados) e avaliando seus resultados. Por fim, os autores defendem a importância do papel das Escolas de Governo na formação da cultura política e de sua adequação aos aspectos particulares de suas áreas de atuação,

[...] possibilitando relações que coordenem, de forma equânime, as ações instrumental e comunicativa, adequando-as ao caso brasileiro e às suas diferentes regiões geográficas, culturais e políticas. Isso depende de como se define sua missão institucional diante dessas pos- 
sibilidades e como se adequa aos processos de formação de opinião e vontade públicas para a consecução de novas formas de gestão pública.

[...] Isso significa que o processo de formação de vontades pela Escola de Governo [...] deve internalizar, também, um espaço democrático, tematizando continuamente a si mesmo, sem fundamentos ou premissas técnico-normativas inquestionáveis, mesmo ligadas à legislação vigente, que pode ou não vir a ser validada pelo processo discursivo. Tal gestão não deve considerar-se como detentora de uma verdade, ainda que provisória, que deve ser depositada nos alunos. A co-gestão já se inicia por um processo pedagógico dialógico, em que os alunos colaboram na formação e fundamentação do saber (GARCIA; SALES, 1999, p. 87-88).

Ao trabalhar a formação e o aprimoramento de servidores de forma holística, tendo-se em mente as competências a serem desenvolvidas em cada caso, as Escolas de Governo passariam a ser um espaço de diálogo, incluindo nos currículos os problemas e dificuldades reais da relação entre cidadãos e os gestores.

\section{CONSIDERAÇÕES FINAIS}

A partir do presente trabalho é possível concluir que o uso da abordagem andragógica pelas Escolas de Governo vem ao encontro da urgente necessidade de desenvolvimento de competências essenciais e de competências de liderança no setor público nas mais diversas esferas. Conforme demonstrado no presente trabalho, os princípios da andragogia permitem a formação do servidor, utilizando o ambiente corporativo e as situações laborais como fonte inestimável de conhecimento e de aprimoramento, não só no nível profissional como também no nível humano, dessa forma promovendo a motivação para o "aprender a aprender".

Ao promover a autonomia do educando, os princípios andragógicos dão instrumentos ao professor para que este trabalhe com o aluno para que ele aprenda a buscar, organizar e analisar novas informações, para que possa integrá-las à sua realidade. Dessa forma, o aluno-servidor percebe que o aprendizado baseado em abordagem andragógica irá ajudá-los na resolução de problemas e tarefas ou a lidar com situações reais do cotidiano profissional.

No caso do desenvolvimento de competências no âmbito das Escolas de Governo, apesar da falta de regulamentação e da disparidade de modelos existentes 
sob essa denominação, é importante salientar a importância de se adotar melhores práticas gerenciais com as devidas adaptações ao contexto do serviço público. Ademais, para se atingir a excelência é preciso ter em mente que a visão reducionista de que o ensino deva focar somente nas informações sobre a instituição e nos mecanismos de interação com a sociedade é insuficiente. É importante que as Escolas de Governo promovam o desenvolvimento holístico de servidores, para que os órgãos possam não somente cumprir suas missões institucionais de forma eficiente e eficaz, mas também formar cidadãos críticos, éticos, engajados, conscientes de seus direitos e deveres, comprometidos com o trabalho e com o seu desenvolvimento pessoal e profissional.

Por fim, a revisão de literatura realizada no presente trabalho procurou fontes diversas, mas não se propôs a exaurir a questão do ponto de vista teórico ou metodológico. Espera-se que este trabalho possa servir como referencial para futuras pesquisas aplicadas, no contexto de programas curriculares voltado para as Escolas de Governo, para que estas se adequem ao contexto de educação para toda a vida e o desenvolvimento de competências profissionais e de liderança de servidores públicos. Devido à natureza da pesquisa exploratória realizada, o presente trabalho não se propõs a extrapolar os achados para situações concretas. Sugere-se a realização de futuros estudos de caso e de pesquisas que busquem comprovar a eficácia e a eficiência do uso da abordagem andragógica por meio dos níveis de avaliação de Kirkpatrick ou por meio de ROI (Retorno sobre o Investimento).

\section{REFERÊNCIAS}

AIRES, R.F.F.; SALGADO, C.C.R.; AYRES, K.V.; ARAÚJO, A.G. de. Escolas de Governo: o panorama brasileiro. Revista de Administração Pública, v. 48, n. 4, p. 1007-1027, jul./ago. 2014. Disponível em: < http://www.scielo.br/scielo.php?script=sci_arttext\&pid =S0034-76122014000400010> . Acesso em: 03 ago. 2017.

BECKER, D.N.; VICENTINI, L.C.; CUNHA, C.J.C.A.; GÜNTHER, H.F. Três caminhos para o desenvolvimento da liderança: uma análise comparativa. Revista Perspectivas Contemporâneas, v. 9, n. 2, p. 167-186, jul./dez. 2014. Disponível em: < http:// revista.grupointegrado.br/revista/index.php/perspectivascontemporaneas/article/ download/1456/621>. Acesso em: 05 maio 2017. 
BRANDÃO, H.P. Aprendizagem, contexto, competência e desempenho: um estudo multinível. 2009. 345f. Tese (Doutorado) - Instituto de Psicologia da Universidade de Brasília. Brasília, 2009. Disponível em: < http://repositorio.unb.br/handle/10482/8322 >. Acesso em: 07 jan. 2017.

BRASIL. Constituição da República Federativa do Brasil de 1988. Disponível em: $<$ http://www.planalto.gov.br/ccivil_03/constituicao/constituicaocompilado.htm > . Acesso em: 05 maio 2017a.

BRASIL. Conselho Nacional de Justiça. Resolução no 192, de 8 de maio de 2014. Dispõe sobre a Política Nacional de Formação e Aperfeiçoamento dos Servidores do Poder Judiciário. Disponível em: < http://www.cnj.jus.br/atos-normativos?documento $=2012>$. Acesso em: 05 mai. 2017b.

BRASIL. Conselho Nacional do Ministério Público. Recomendação no 52, de 28 de março de 2017. Recomenda aos órgãos que compõem o Ministério Público brasileiro que implementem a Política Nacional de Gestão de Pessoas, mediante a edição do correspondente ato administrativo. Disponível em: < http://www.cnmp.mp.br/ portal/atos-e-normas/norma/4890 > . Acesso em: 05 mai. 2017c.

BRASIL. Decreto $\mathbf{n}^{\mathbf{0}} \mathbf{5 . 7 0 7}$, de 23 de fevereiro de 2006. Institui a Política e as Diretrizes para o Desenvolvimento de Pessoal da administração pública federal direta, autárquica e fundacional, e regulamenta dispositivos da Lei $\mathrm{n}^{0} 8.112$, de 11 de dezembro de 1990. Disponível em: < http://www.planalto.gov.br/ccivil_03/_ato20042006/2006/decreto/d5707.htm > . Acesso em: 05 mai. 2017d.

BRASIL. Tribunal de Contas da União. Acórdão no 3.023/2013 - Plenário, no Processo $n^{0}$ 022.577/2012-0. Relator: COSTA, Marcos Bemquerer. Publicado no DJ de 21/11/2013, p. 89. Disponível em: < https://www.jusbrasil.com.br/diarios/61945559/ dou-secao-1-21-11-2013-pg-89> . Acesso em: 05 maio 2017e.

CAPUANO, E. A. Gestão por competências no setor público: experiências de países avançados e lições para o Brasil. Revista do Serviço Público, Brasília, v. 66, n. 3, p. 371-394, jul./set. 2015. Disponível em: < http://repositorio.enap.gov.br/bitstream/ handle/1/2386/Gest\%C3\%A3o\%20por\%20compet\%C3\%AAncias\%20no\%20setor\%20 p\%C3\%BAblico_experi\%C3\%AAncias\%20de\%20pa\%C3\%ADses\%20avan\%C3\%A7a- 
dos\%20e\%20li\%C3\%A7\%C3\%B5es\%20para\%20o\%20Brasil.pdf?sequence=1\&isAllowed $=\mathrm{y}>$. Acesso em: 05 maio 2017.

CARBONE, P.P.; BRANDÃO, H.P.; LEITE, J.B.D.; VILHENA, R.M.P. Gestão por competências e gestão do conhecimento. Rio de Janeiro: FGV, 2009.

CARDOSO, I.M. Andragogia em ambientes virtuais de aprendizagem. 2006. $158 \mathrm{f}$. Dissertação (Mestrado) - Programa de Pós-Graduação em Educação da Pontifícia Universidade Católica de Minas Gerais, Belo Horizonte, 2006. Disponível em: < http:// www.biblioteca.pucminas.br/teses/Educacao_CardosoIM_1.pdf $>$. Acesso em: 19 jan. 2017.

CHRISPIM, A.C.D.; TORRES, W. A capacitação e a gestão por competências como ferramenta para o desenvolvimento institucional da administração fazendária no âmbito da Receita Federal do Brasil. Cadernos de Finanças Públicas, Brasília, n. 14, p. 5-68, dez. 2014.

COSSON, R. Escolas de Governo: nove questões para pensar o lugar da educação para a democracia. Seminário Virtual de Escolas de Governo: compartilhando experiêncas. Belo Horizonte: [s.n.], 2016.

DEAQUINO, C.T.E. Como aprender: andragogia e as habilidades de aprendizagem. São Paulo: Pearson Prentice Hall, 2015.

DURÁN, M.H.C. A motivação dos peritos criminais das unidades técnico-científicas da Polícia Federal na Bahia. 2012. 103f. Dissertação (Mestrado) - Escola Brasileira de Administração Pública e de Empresas da Fundação Getúlio Vargas. Rio de Janeiro, 2012. Disponível em: < http://bibliotecadigital.fgv.br/dspace/bitstream/ handle/10438/10030/Dissertacao\%20Maria\%20Helena\%20Duran\%20versao\%20final.pdf?sequence $=1>$. Acesso em: 07 jul. 2017.

FERNANDES, C.C.C. Escolas de governo: origens e trajetória do tema no Brasil. In: FERNANDES, C.C.C.; PALOTTI, P. L. M.; CAMÕES, M.R.S. (Org.). Escolas de governo: perfis, trajetórias e perspectivas. Cadernos Enap, v. 1, n. 43, 2015. Disponível em: $<$ http://www.enap.gov.br/pt/web/pt-br/cadernos-enap > . Acesso em: 24 jul. 2017. 
GARCIA, M.V.; SALES, R. O papel da escola de governo na construção de uma nova relação entre Estado e Terceiro Setor: da desconfiança à parceria. Revista Paranaense de Desenvolvimento, Curitiba, n. 96, p. 77-89, maio/ago, 1999. Disponível em: < http://www.ipardes.gov.br/pdf/revista_PR/96/vileni.pdf > . Acesso em: 23 fev. 2017.

GRAMIGNA, M.R. Modelo de Competências e Gestão de Talentos. São Paulo: Makron Books, 2002.

MASETTO, M.T. Inovação na aula universitária: espaço de pesquisa, construção de conhecimento interdisciplinar, espaço de aprendizagem e tecnologias de comunicação. Perspectiva, v. 29, n. 2, 597-620, jul./dez. 2011. Disponível em: < https:// periodicos.ufsc.br/index.php/perspectiva/article/download/2175-795X.2011v29n2p597/22219> . Acesso em: 05 maio 2017.

MEISTER, J.C. Educação corporativa: a gestão do capital intelectual através das universidades corporativas. São Paulo: Pearson Makron Books, 1999.

MERRIAM, S.B.; CAFFARELLA, R.S.; BAUMGARTNER, L. M. Learning in adulthood: a comprehensive guide. 3. ed. San Francisco: Jossey Bass, 2007.

PACHECO, R.S. Escolas de governo como centros de excelência em gestão pública: a perspectiva da ENAP - Brasil. Revista do Serviço Público, Brasília, v. 53, n. 1, p. 7588, jan./mar. 2002. Disponível em: < http://repositorio.enap.gov.br/bitstream/handle $/ 1 / 1914 / 2002 \% 20 \mathrm{Vol} .53 \% 2 \mathrm{cn} .1 \% 20 \mathrm{Pacheco}$. pdf?sequence $=1 \&$ isAllowed $=\mathrm{y}>$. Acesso em: 05 maio 2017.

RANZINI, M.S.; BRYAN, N.A.P. Capacitação e formação para o setor público e os modelos de Escola de Governo no Brasil. Revista do Serviço Público. Brasília: ENAP. v. 68 , n. 2, p. 417-438, abr./jun. 2017. Disponível em: < https://revista.enap.gov.br/ index.php/RSP>. Acesso em: 21 jul. 2017.

SHINODA, A.C.M.; TUMELERO, C.; MERINO, M.H; DANESE, A.M.; CARNAÚBA, A.A.C.; MARINHO, B.L. Um estudo sobre a utilização de andragogia no ensino de pós-graduação em administração. REGE, v. 21, n. 4, p. 507-523, out./dez. 2014. Disponível em: < http://www.revistas.usp.br/rege/article/download/99953/98443>. Acesso em: 05 maio 2017. 
SOUZA, L.R.S. Liderança: impactos positivos e negativos sobre o potencial criativo das pessoas no ambiente organizacional. Revista da Católica, v. 3, n. 5, jan./jul. 2011. Disponível em: < http://catolicaonline.com.br/revistadacatolica2/artigosv3n5/ artigo07.pdf $>$. Acesso em: 30 dez. 2016.

TAKEUCHI, H.; NONAKA, I. Criação e Dialética do Conhecimento. In: TAKEUCHI, H.; NONAKA, I. (Org.). Gestão do conhecimento. Porto Alegre: Bookman, 2008.

TARAPANOFF, K. (Org.). Aprendizado organizacional: contexto e propostas. Curitiba: Intersaberes, 2012. vol. 2.

UNESCO. Educação: um tesouro a descobrir - Relatório para a UNESCO da Comissão Internacional sobre Educação para o século XXI. São Paulo: Ed. Cortez, 1996. Disponível em: <http://dhnet.org.br/dados/relatorios/a_pdf/r_unesco_educ_tesouro_descobrir.pdf > . Acesso em: 25 jan. 2017.

Recebido em: 01/03/2018 Aceito em: 29/03/2018 